\title{
End User Concern about Security and Privacy Threats
}

\author{
Joshua B. Gross and Mary Beth Rosson \\ College of Information Sciences and Technology311B IST Building \\ The Pennsylvania State University \\ 311B IST Building \\ University Park, PA 16802 \\ jgross@ist.psu.edu, mrosson@psu.edu
}

\begin{abstract}
End users are typically seen as the weakest link in ensuring security and privacy in computing environments. Our own prior work suggested that end users may have difficulty differentiating between privacy/security problems and other hardware/software concerns. However, a survey of a broad group of internet users showed that, in fact, these users believe that they can not only differentiate between these two sets of concerns, but that in fact users are more concerned with security/privacy concerns than they are with other types of computer problems.
\end{abstract}

\section{INTRODUCTION}

In an ideal world, end users would be protected from all potential security threats: email would filter spam, web browsers would identify phishing sites, and firewalls and other filters will prevent any malware from infecting a computer. However, this is an overly idealistic view; it is currently not possible for security, and due to personal preferences, it may never be possible for privacy.

As a result, all users, including the ubiquitous end user (having no special qualification other than using a computer) must take a role in managing security and privacy. However, asking users to take such a role, even if demanded by the reality of the world, has a cost. As one participant in an earlier study commented "the details are ... incomprehensible."

Unfortunately, an earlier interview study [3] raised a worrying possibility, namely that users perceive security and privacy threats as synonymous with other computer hardware and failures. This led to the concern that users might respond similarly to, for example, a malware infection as a hardware failure.

One motivation for this concern was a specific episode reported in the interview study. One participant mentioned that when her parents had a computer infected with a virus, their ultimate solution was to replace the computer. While this technically solves the problem, it was probably unnecessary, and may have created a problem of personal data being left on the hard drive [2].

Limited prior fieldwork in this area [1] has left many unanswered questions. A key purpose of the broader survey study reported here is to determine the the extent to which phenomena observed in the interview study are present in the population at large.

Copyright is held by the author/owner. Permission to make digital or hard copies of all or part of this work for personal or classroom use is granted without fee.

Symposium On Usable Privacy and Security (SOUPS) 2007, July 18-20, 2007, Pittsburgh, PA, USA.
To this end, we wished to know to whether or not end users conflate security/privacy problems with other common computer problems. We believe this is an important question, because the answer will help to develop privacy/security tools that leverage a user's understanding. Thus, our research question was: Do end users differentiate between privacy/security problems and other computer problems?

\section{METHOD}

Our primary source of data was a survey of end users $(n=368)$ conducted using SurveyMonkey ${ }^{1}$, with participants recruited via StudyResponse ${ }^{2}$. The only conditions we placed on recruitment were that respondents be employed adults (over 18) who are current internet users. We sent recruitment emails to 2,000 potential participants, using a drawing of a small number of $\$ 25$ gift certificates to encourage responses. The survey contained over 150 questions, although this brief abstract considers only a small subset. The survey was based on findings from an interview study [3] designed to capture real-world end user perception.

\subsection{Respondent Profile}

We received 368 unique responses for a response rate of $18.4 \%$. Despite the standard concerns of self-selection in survey data, we observed a wide range of respondent demographics. Space limitations prevent us from detailing these data, but the range of computer and Internet experience shown Table 1 are two useful indicators of population variability.

Table 1. Large Variance in Computer Experience

\begin{tabular}{|l|l|l|}
\hline \multicolumn{1}{|c|}{ Question } & \multicolumn{1}{|c|}{ Mean (SD) } & \multicolumn{1}{c|}{ Range } \\
\hline Years using computers & $11.97(6.38)$ & $1-39$ \\
\hline Years using Internet & $8.14(3.64)$ & $0-25$ \\
\hline
\end{tabular}

\subsection{Concern Questions}

To capture the degree to which users are concerned about specific problems, we asked participants to rate their concern on 13 issues (Table 2). Of these, we classified concerns 1-8 as related to privacy/security, and items $9-13$ as general computer concerns. The responses were captured on a 7-point Likert-type scale ranging from 1 (Very unconcerned) to 4 (Neither concerned nor unconcerned) to 7 (Very concerned). The items, mean response values, and standard deviations are reported in Table 2, which suggests that illegitimate links in email or web pages are especially worrisome, whereas remembering passwords is a less problematic topic.

\footnotetext{
${ }^{1} \mathrm{http}: / /$ www.surveymonkey.com/s.asp?u=967232635213

${ }^{2}$ http://istprojects.syr.edu/ studyresponse/studyresponse/index.htm
} 
Table 2. Concern Questions and Response Values

\begin{tabular}{|l|l|l|}
\hline \multicolumn{1}{|c|}{ Concern } & Mean (SD) & Group \\
\hline $\begin{array}{l}\text { 1. An email or web page may use an } \\
\text { illegitimate mechanism to gather personal } \\
\text { information about me. }\end{array}$ & $5.23(1.80)$ & Priv/Sec \\
\hline $\begin{array}{l}\text { 2. I may unknowingly allow access to } \\
\text { confidential data. }\end{array}$ & $4.94(1.97)$ & Priv/Sec \\
\hline 3. I may be a victim of identity theft. & $4.77(2.00)$ & Priv/Sec \\
\hline $\begin{array}{l}\text { 4. Monitoring software may create records of } \\
\text { my online behavior. }\end{array}$ & $4.62(1.91)$ & Priv/Sec \\
\hline $\begin{array}{l}\text { 5. One of my passwords may be guessed or } \\
\text { "cracked" by others. }\end{array}$ & $4.60(1.99)$ & Priv/Sec \\
\hline $\begin{array}{l}\text { 6. My computer may have a virus that I do } \\
\text { not know about. }\end{array}$ & $4.57(2.05)$ & Priv/Sec \\
\hline $\begin{array}{l}\text { 7. Unauthorized software or persons may } \\
\text { access my data files. }\end{array}$ & $4.57(1.98)$ & Priv/Sec \\
\hline 8. My computer is unsecure. & $4.96(1.90)$ & General \\
\hline 9. My computer software will fail. & $4.80(1.90)$ & General \\
\hline 10. My computer hardware will fail. & $4.59(1.91)$ & General \\
\hline 11. I may lose crucial files. & $4.98)$ & General \\
\hline 12. I may lose crucial emails. & Priv/Sec \\
\hline 13. I will forget a password. & & \\
\hline
\end{tabular}

\section{RESULTS}

To determine whether or not end users differentiate between general computer concerns and privacy/security-specific concerns, we a factor analysis on the 12 items. Using a Varimax rotation and extracting all factors with an Eigenvalue over 1, we discovered two reliable components that suggest that respondents did rate general concerns differently from privacy/security concerns. As summarized in the third column of Table 3, the factor analysis revealed two sets of items, one corresponding to privacy/security concerns, and one to general computer concerns.

We also examined the reliability of the two sets of items. Our first scale, which we call Privacy/Security Concern (the first eight variables in Table 3) had a Cronbach's $\alpha=.92$ and a mean of 4.69 $(\mathrm{SD}=1.57)$. The second, which we call General Computer Concern (the last five variables in Table 3), had a Cronbach's $\alpha=$ .89 , and a mean of $4.39(\mathrm{SD}=1.63)$. A paired-sample t-test showed that the two were significantly different $\left(\mathrm{t}\left(345^{3}\right)=4.25, p<.001\right)$, suggesting that end users are more concerned with privacy and security issues than general computer failure.

\section{ANALYSIS AND FUTURE DIRECTIONS}

Our analysis clearly shows that users do differentiate between security/privacy concerns and general computer concerns, thus confirming our hypothesis. There are some limitations to these data, which we will discuss, along with our goals for future work.

First, the means between the two scales were not dramatically different, and, as our hypothesis does not incorporate a relationship with an independent variable, we can make no claim

${ }^{3}$ The smaller DF is due to a smaller number of participants who completed all questions in the given section.
Table 3. Factor Analysis of Computer Concerns

\begin{tabular}{|l|c|c|c|}
\hline \multicolumn{1}{|c|}{ Question } & C1 & C2 & Scale \\
\hline $\begin{array}{l}\text { 2. I may unknowingly allow access to } \\
\text { confidential data. }\end{array}$ & .828 & .178 & Priv/Sec \\
\hline $\begin{array}{l}\text { 7. Unauthorized software or persons may } \\
\text { access my data files. }\end{array}$ & .809 & .305 & Priv/Sec \\
\hline $\begin{array}{l}\text { 1. An email or web page may use an } \\
\text { illegitimate mechanism to gather personal } \\
\text { information about me. }\end{array}$ & .787 & .176 & Priv/Sec \\
\hline 8. My computer is unsecure. & .756 & .287 & Priv/Sec \\
\hline 3. I may be a victim of identity theft. & .747 & .369 & Priv/Sec \\
\hline $\begin{array}{l}\text { 5. One of my passwords may be guessed } \\
\text { or "cracked" by others. }\end{array}$ & .714 & .341 & Priv/Sec \\
\hline $\begin{array}{l}\text { 6. My computer may have a virus that I do } \\
\text { not know about. }\end{array}$ & .703 & .338 & Priv/Sec \\
\hline $\begin{array}{l}\text { 4. Monitoring software may create records } \\
\text { of my online behavior. }\end{array}$ & .620 & .352 & Priv/Sec \\
\hline 9. My computer software will fail. & .265 & .881 & General \\
\hline 10. My computer hardware will fail. & .267 & .855 & General \\
\hline 11.I may lose crucial files. & .321 & .818 & General \\
\hline 12. I may lose crucial emails. & .244 & .609 & General \\
\hline 13. I will forget a password. & & & \\
\hline
\end{tabular}

about effect size. However, the factor analysis and T-test do show a marked difference.

It is impossible to tell from these data whether or not users can employ these differences in practical ways to protect themselves. Some of the additional survey data should help to address this question, but we anticipate that an observational study (e.g. in a laboratory setting) will help to determine how we might build on users' concerns in designing tools for better ensuring privacy and security.

Finally, the survey data did not reveal any differentiation between privacy and security concerns. Generally accepted definitions for this difference are difficult to find, and other data from our survey (to be published later) suggest that the two are often conflated. It is not clear yet whether this conflation is problematic.

\section{ACKNOWLEDGMENTS}

The authors would like to thank all of the survey respondents. Work was funded by the NSF through the EUSES grant CCF0405612 (http://eusesconsortium.org).

\section{REFERENCES}

[1] de Paula, R., Ding, X., Dourish, P., Nies, K., Pillet, B., Redmiles, D.F., Ren, J., Rode, J.A. and Filho, R.S. In the eye of the beholder: A visualization-based approach to information system security. International Journal of Human-Computer Studies, 63. 5-24.

[2] Garfinkel, S.L. and Shelat, A. Remembrance of data passed: a study of disk sanitization practices IEEE Security \& Privacy, 2003, 17-27.

[3] Gross, J.B. and Rosson, M.B. Looking for Trouble: Understanding End-User Security Management CHIMIT, ACM, Cambridge, MA, 2007. 